\title{
Open access, open source and e-theses: the development of the Edinburgh Research Archive
}

Richard Jones and Theo Andrew

Authors

Richard Jones. University of Bergen, Bergen, Norway. E-mail:

Richard.jones@ub.uib.no

Theo Andrew. Edinburgh University Library, Scotland, UK E-mail:

theo.andrew@ed.ac.uk

\begin{abstract}
Keywords: E-theses; Open access; Open source; Institutional repositories; DSpace; Edinburgh Research Archive

Word length: 5,204

$<$ The Theses Alive project, conducted at Edinburgh University Library, aimed to produce an E-Theses repository with a view to providing a solution which may be appropriate for other UK higher education institutions to adopt. This paper examines some of the most interesting and involved areas of that project, including what open access and open source meant for it, and how the Edinburgh Research Archive, an institutional repository of E-Theses and E-Prints, grew out of it>.
\end{abstract}

\section{Introduction and background}

The practice of making digital versions of theses and dissertations available online is growing internationally. Repositories of Electronic Theses and Dissertations (ETDs) are now becoming common in universities across the world. Data from these repositories suggest a dramatic increase in the use and citation of doctoral theses in current research activity, and this is related to the enhanced resource discovery and access that the digital surrogate confers. One of the major sources of inspiration and technical /cultural help for setting up electronic theses (or e-theses) collections is the Networked Digital Library of Theses and Dissertations (NDLTD), an international organisation dedicated to promoting the adoption, creation, use, dissemination and preservation of e-theses (http://www.ndltd.org).

In the UK the Joint Information Systems Committee (JISC) Focus on Access to Institutional Resources (FAIR) Programme was launched in August 2002 to investigate the disclosure of institutional assets, including ETDs, and to gather intelligence about and increase understanding of the technical, organisational and cultural challenges of these processes (Awre, 2004).

As part of this programme, between November 2002 and November 2004, the Theses Alive! project at Edinburgh University Library (EUL) examined and developed mechanisms for e-theses collections in UK higher education (HE) institutions. Theses Alive! was one of three projects related to e-theses funded within the FAIR Programme. The other projects were: 
- Electronic Theses Project which involved a consortium led by The Robert Gordon University in Aberdeen, Scotland (http://www2.rgu.ac.uk/library/e-theses.htm)

- DAEDALUS (http://www.lib.gla.ac.uk/daedalus/)) at Glasgow University Library, also in Scotland.

Theses Alive! showed, by building a proof-of-concept service -the Edinburgh Research Archive (ERA) - that an e-theses development programme is an extremely worthwhile endeavour, and is a viable proposition for most UK HE institutions (Andrew, Jones and MacColl, 2005). Staff at EUL were also involved in the JISCfunded Securing a Hybrid Environment for Research Preservation and Access (SHERPA) project. SHERPA investigated repositories for storing different types of research material, with a focus on e-prints. It made sense that the outcome of both of these projects in Edinburgh be part of the same new service - a single repository, namely the ERA. Figure 1 shows a screenshot of the opening page of the ERA which has been an active service since June 2004.

Take in Figure 1.

Figure 1. Opening page of the ERA Web site

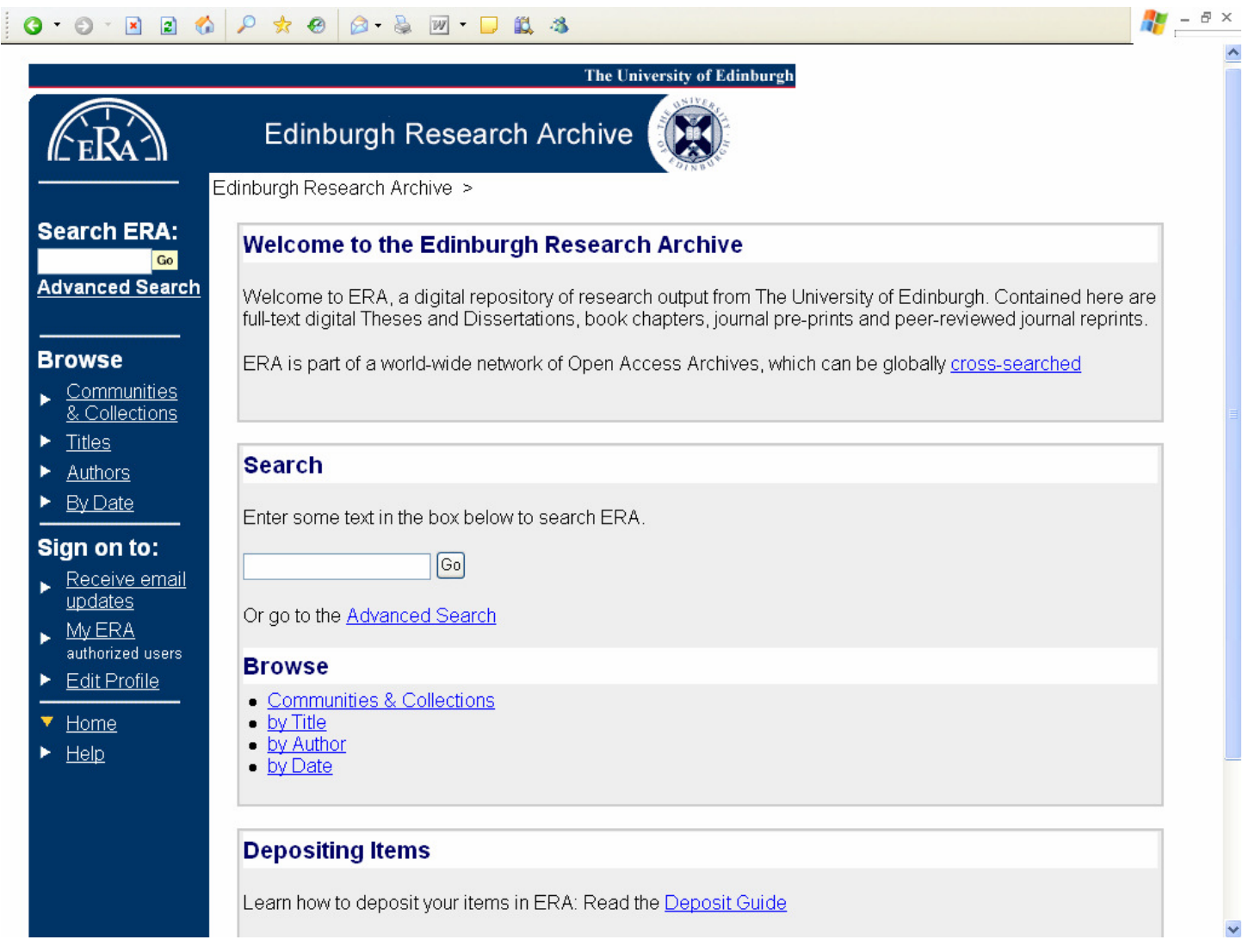

As can be seen in Figure 1, the ERA is a digital repository of various research output from the university including ETDs, book chapters, journal pre-prints and journal reprints. Figure 2 shows brief details of some of these items added to the ERA in early 2005.

Take in Figure 2. 
Figure 2. Recent items added to the ERA

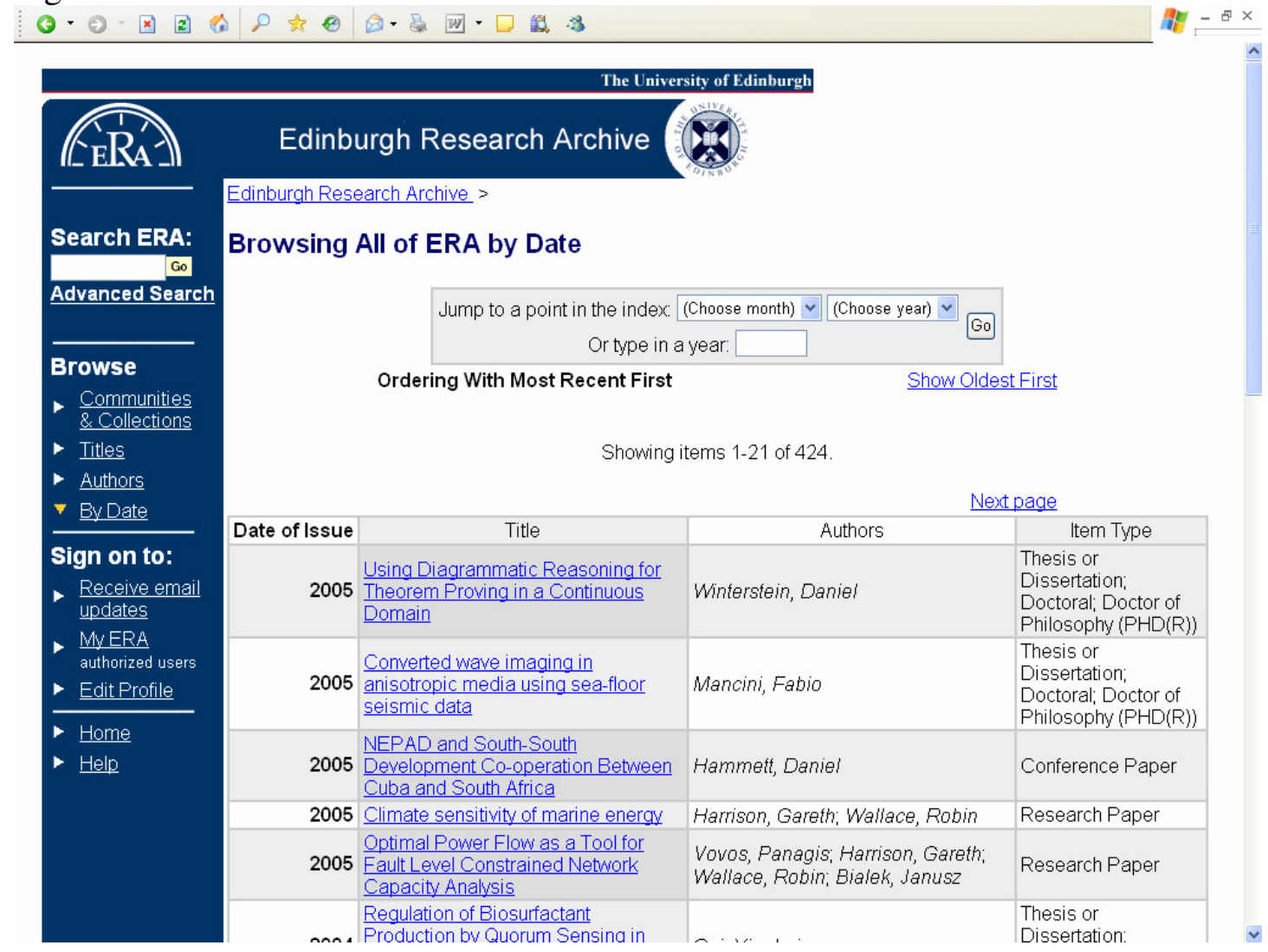

\section{Open access: implications for e-theses and decisions made within the ERA}

The most commonly accepted and succinct definition of open access literature is that it should be digital, online, free of charge, and free from most copyright and licensing restrictions (Suber, 2005). In contrast, the traditional doctorate theses literature has gained a reputation for being intractable, and despite obvious research value it remains part of the 'grey literature' - hard to trace and virtually invisible in an age when wider and easier access to scholarly and scientific literature through the provision of e-journals, e-books, and open access repositories is possible.

Although e-theses promise to deliver a whole host of academic and operational benefits, there are a number of technical, academic and cultural complications that need to be addressed as theses are transferred from the bookshelf to the Web. The main academic-related key issues that have been encountered so far include:

- revision of the current examination process

- perceived threats of plagiarism and bogus submissions

- intellectual property (Green \& Powell, 2005).

Overcoming the intellectual property issue (IP) is proving to be one of the most challenging tasks. Within the meaning of the Copyright, Designs and Patents Act 
(CDPA), 1988, a British thesis is an unpublished work, and is protected under the Act as such. The Act prohibits re-publication of any significant part of a thesis by a third party without the copyright owner's consent. Furthermore, copies of a thesis cannot be issued to the public without the copyright owner's consent. In any legal sense making something available on the Internet is publishing, which creates an unusual and interesting dichotomy for the thesis literature (Andrew, 2004). As a consequence organisational requirements and procedures need to be clarified and updated.

A secondary complication concerns how to deal with embedded material within the thesis, such as text, images and associated sound files, which may have been created by a third party copyright holder. The 'fair dealing' ('fair-use' in North America) defence essentially allows limited copying without permission provided it is fair and the commercial interests of the rights holder are not damaged. The fair dealing precedent for theses that has been set extends to examination and research; however, as soon as the thesis is published then a potential breach of copyright could occur.

There are also considerations as to what happens after the thesis has been made available on the Web. Many authors are aware of the potential problems of undetected plagiarism and would like reassurance and assistance in this matter.

Finally, a thesis may be politically or commercially sensitive, or the author may be seeking to publish a significant portion or extracts of the thesis as a book or a journal article. In situations like this it may be desirable to restrict access to the work for a period of time; on average only two theses per year are restricted at the University of Edinburgh in the College of Science and Engineering.

The solution EUL has adopted to address the problems of licences is to implement a robust licensing system upon submission of a thesis, or other forms of relevant digitised documents such as e-prints, to the ERA. When students (or others) submit their material to the ERA they are asked to agree to a three part licence, consisting of:

- Deposit licence: this gives EUL the non-exclusive right to hold, disseminate and preserve the e-thesis. The 'submitter' also warrants that the content does not breach any laws including defamation, libel and copyright.

- Use Licence: this clearly defines what rights end users have to downloaded material, e.g. reproduction and access, and to remind end users of any restrictions placed on the item, thereby giving submitters/institutions some protection against plagiarism or changes to the content. The licence is the UK version of the Creative Commons 'Attribution-Non Commercial-Share Alike' licence (http//creativecommons.org).

- Restriction Licence: this offers the submitter the chance to mark the material as restricted, and to apply a correct legal form of words to satisfy Freedom of Information Act requirements, which will ensure the item stays restricted.

The decision to use Creative Commons (CC) was made partly to support the open access movement, by allowing generous end-user rights, but also to simplify future rights and permissions procedures. This frees access to the material, and removes the need for constant correspondence requesting permission to perform actions for which the submitter is usually always happy. It does not dilute the submitter's copyright 
status, and is flexible, in that any of these conditions can be waived if permission from the copyright holder is granted.

In conclusion, delivering open access status to the thesis literature is an attractive proposition and possible in principle, but special attention must be given to the legal implications as the situation can be complicated and difficult to resolve in practice.

\section{Open source software: implications for e-theses and decisions made within the ERA}

It makes sense when following the ethos of the open access movement, to simultaneously endorse the open source movement. Both have similar objectives with open source concentrating, as the name suggests, on access to the source code for the software. The irony of choosing a closed source, or proprietary package to achieve an open access objective can hardly be overlooked, although special programming support may be necessary to implement open source software.

During the development of the ERA there was no debate over whether or not to adopt open source software (OSS) and it is also recommended by JISC (JISC, 2001). The reasons for choosing OSS were:

- zero cost of acquisition

- ability to use software for whatever purpose

- ability to adapt software to meet local requirements

- ability to distribute changes to the software.

It is important to note that although the cost of acquiring the software was zero the total cost of ownership was a different matter. It was necessary for EUL to employ software professionals to tailor and develop the OSS for the ERA and this is costly. A number of packages have been developed for developing IRs (Open Society Institute, 2004). The main OSS considered for the ERA were:

- DSpace (http://www.dspace.org), developed by the Massachussetts Institute of Technology (MIT) Libraries and Hewlett-Packard;

- EPrints.org (http://www.eprints.org) developed at the University of Southampton

- ETD-db (http://scholar.lib.vt.edu/ETD-db/) from Virginia Tech in the US, where staff had been involved in the development of ETDs since the early 1990s.

Staff at the DAEDALUS project carried out an evaluation of EPrints.org and DSpace (Nixon, 2003 whereas an evaluation of DSpace and ETD-db was undertaken at Edinburgh (Jones, 2003). The results indicated that ETD-db, although well featured for e-theses was insufficient to support materials other than e-theses, while DSpace and EPrints.org performed fairly equally. A decision to use DSpace for ERA was taken not least because of the rapidly growing community surrounding it.

OSS does not, without licensing information, mean very much, and there are many licence options that can be adopted. The two main types are 'permissive' and 'copyleft'. Both of these provide access to the source code, but copyleft enforces freedoms on future and derived source code, while permissive does not. There are a number of licences which met the requirements for the ERA; the Gnu General Public License (GPL) and the Lesser GPL (LGPL) (Stallman, 2002) are the 
community standards for copyleft, whilst the most commonly used permissive licence is the Berkeley Source Distribution (BSD) licence (FreeBSD, 2003).

DSpace is available under a BSD licence and has been customised for use with the ERA. DSpace is used in many organisations throughout the world. The source code is maintained in a version-controlled repository on a public Web server so that any user may obtain a copy of the most current software. A number of individuals have administrative control over this repository and are referred to as 'committers'; their job is to both develop the software and to vet submissions of software amendments from others. Periodically a version of the source will be declared stable and released as a package for those not interested in or capable of working with the developmental versions.

Extra software tools have been developed within ERA for DSpace, without having to continually liaise with the originators. This has allowed experimentation and development in ways not possible with commercial packages. The result is a software package known as Tapir (Theses Alive Plug-In for Institutional Repositories) which is also made available under a BSD licence.

\section{Tapir: an open source animal for the ERA}

The objective of Tapir was to develop a software package based on DSpace which could deliver the functionality demanded by the ERA (Jones, 2004). In order to do this the developmental version of the source code for DSpace was used. Tapir was developed as an entity totally separate from DSpace for the following reasons:

- it was not assumed that developments in Edinburgh would be of interest to the whole of the DSpace community;

- the developmental model of DSpace at the time the project began (2002) was not as open as it is now;

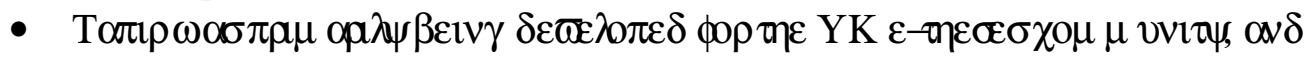
development was not expected to move at the same speed or direction as DSpace development.

Tapir, therefore, has its own open access version-controlled repository but does not use the same developmental model as DSpace. Instead development is controlled by EUL, although other organisations may take the source code, change it as they see fit, and re-release it to the community. The main reason for this was that during the course of the Theses Alive! project EUL needed to control the direction of development. Now that the project has finished it is expected that much of the Tapir source code will be submitted to the DSpace core as part of Edinburgh's ongoing commitment to the community and due to the fairly widespread interest in the work undertaken.

Specific key features were identified for dealing with e-theses at Edinburgh which included the need for identification of the type of content in the institutional repository (IR) as well as supervisor access and metadata and submission procedures as described in the following sub-sections. All features have been implemented and further developments are being considered to further enhance the functionality of the ERA, such as statistical analysis of usage and integration into cross-searching systems. 


\subsection{Supervisor access}

The requirement was to allow supervisors to observe the work of students, to make changes, suggestions or comments prior to submission of the thesis. For this a supervision order system was developed which has the following functionality:

- Collaborative workspace: items in the process of being submitted appear in both the supervisor's and student's private workspaces. This is good for integrating e-theses into a traditional IR because the supervisor can also be simultaneously authoring other documents in this workspace and be supervising more than one thesis.

- Working item viewing: supervisors with insufficient privileges to edit a student's submission should be able to observe the ongoing work. This is the sort of functionality that might be required by external advisors.

- Notes: to allow online, recorded, communication between students and supervisors.

- Administrative tools: to administer supervision orders that provide the above functionality. This includes an authorisation tool to provide different types of supervision.

A variety of policies regarding the role of supervisors with respect to the workspace item have been defined:

- None: Supervisors have no authorisation regarding the workspace item.

- Editor: Supervisors have full editorial control over the item. This gives them precisely the same authorisations as the student ( or the owner) of the item.

- Observer: The supervisors may only observe the metadata and files of the item, but cannot make changes.

A linking facility was provided which allows the administrator to create a singular relationship between the three system entities: the supervisor group, the workspace item, and the policy settings.

Supervisors and students have personalised ERA pages ('My ERA') listing items which they are supervising or authoring, with clear labels to that effect.

\subsection{Metadata and submission}

In collaboration with other projects funded as part of FAIR a metadata set for e-theses in UK institutions was developed (Electronic Theses Project, 2003) and this is used within Tapir. Figure 3 shows the metadata for an e-theses in the ERA.

Take in Figure 3

Figure 3. Metadata for an item in the ERA 


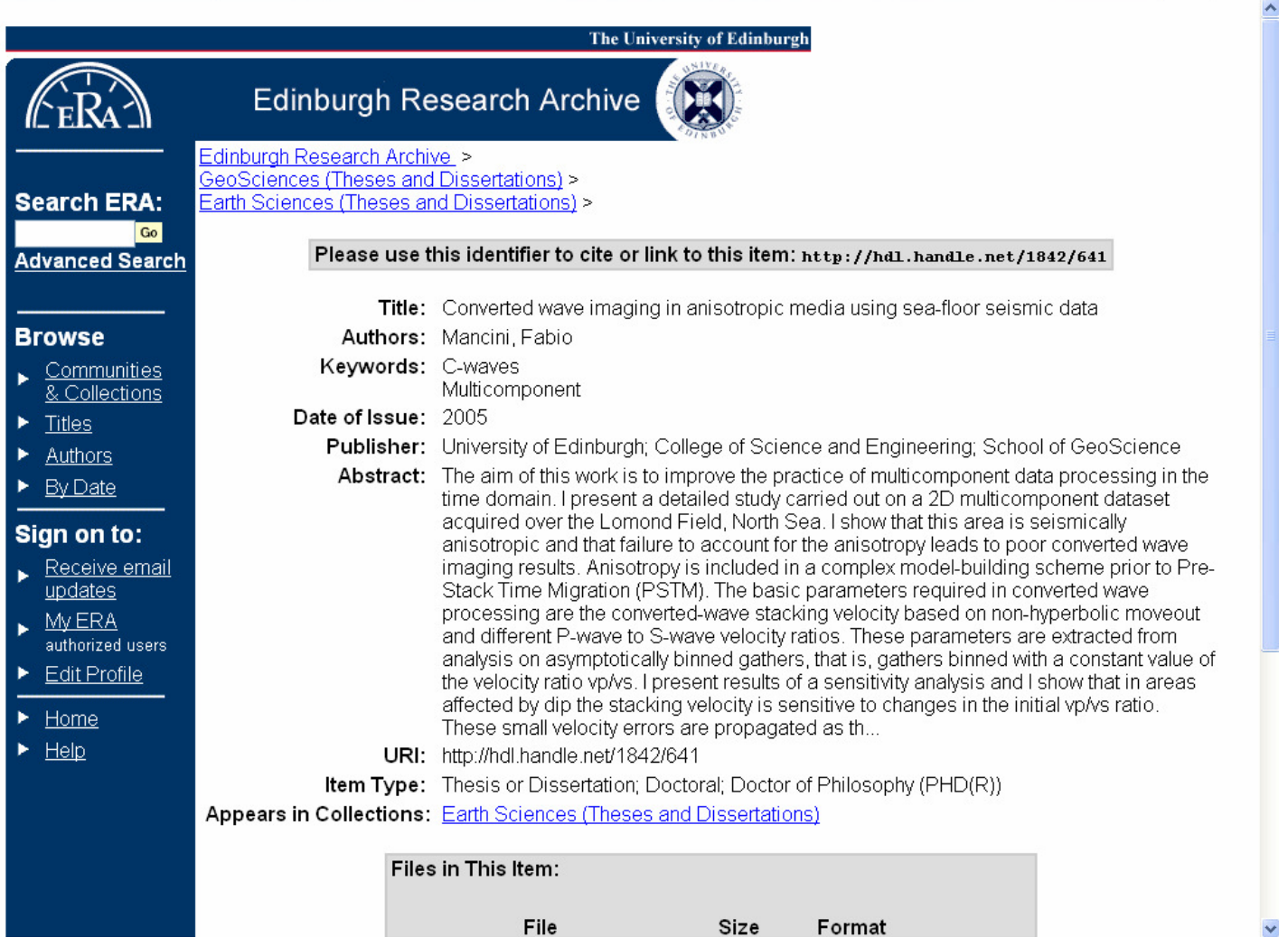

Devising a new submission system for DSpace to deal with a variety of types of material was straightforward enough, although there is a strong case to be made for redesigning the entire submission system to cater for customisable metadata and some development in this area is underway within the DSpace community. The objective of the submission system using this metadata set is to enable it to sit alongside one or more other submission systems, within the same overall system, so as to allow multipart licences and automatically apply access restrictions where necessary.

In dealing with licensing and subsequent restrictions, the concepts that need to be considered are:

- the range of parties involved - the submitter, the institution and the end user;

- the restrictions are not necessarily absolute (they may have time or domain dependencies).

The six restriction types that the submitter can specify in the ERA, using Tapir, are:

- None - no restriction on access

- Domain, 1 year - restricted to institutional domain for one year

- Domain, 2 years - restricted to institutional domain for two years

- Withheld, 1 year - restricted from all for 1 year

- Withheld, 2 years - restricted from all for 2 years

- Withheld permanently - restricted from all forever.

The process of building the licence is shown in Figure 4. All items have a deposit licence, then time-dependent licences are applied for domain-restricted and nonpermanently restricted items, which then also have a restricted licence appended. For non-restricted items the simple end-user licence is appended.

Take in Figure 4

Figure 4. Procedure flow for constructing multi-part licences 


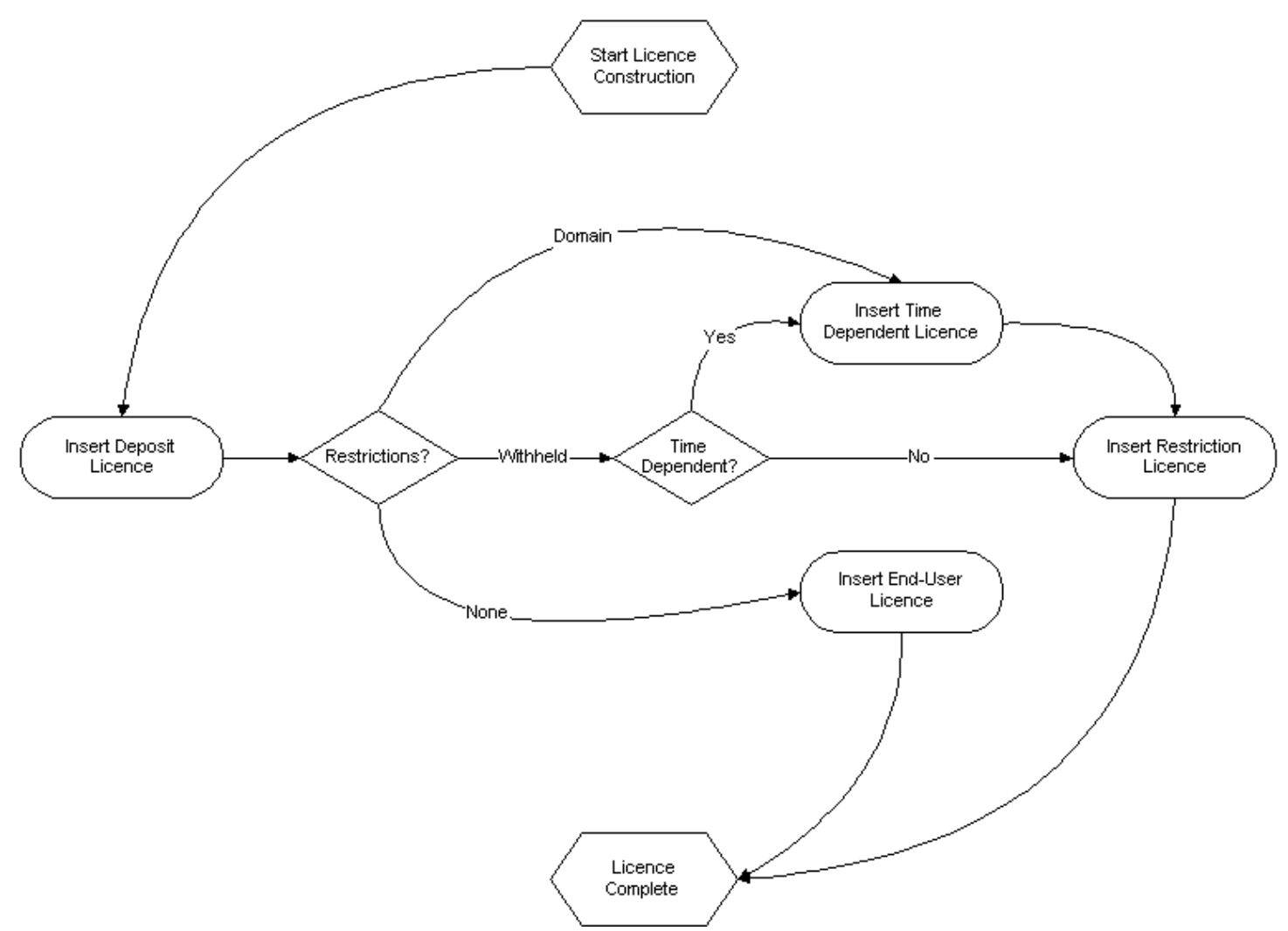

To provide the restriction required the item is withdrawn from the repository, allowing it to exist without being available to any users other than administrators. Domain restriction is currently not supported by Tapir and has to be manually applied to the Web server software on a case by case basis; this is not such a serious problem as may first appear since the number of domain restricted items is extremely low.

\section{Further experiences with the ERA}

The initial objective was to create a repository containing theses, but the ERA has achieved significantly more as it is also capable of (and appropriate for) handling many other types of electronic resource (such as e-prints, conference papers/posters and technical reports). The ERA also offers additional features such as persistent identifiers and a platform from which digital preservation efforts can be launched (Wheatley, 2003). With the ERA service developed it was necessary to develop methods of obtaining content and encouraging its use.

A difficulty arose when attempting to define the branding for ERA in the university. The initial design was to look as similar to the EUL Web site as possible, in an attempt to provide a relatively seamless transitional navigation between the two systems. However, there has been concern that branding ERA as a library service may put off potential users or departments from endorsing the service. In addition, the design of the EUL Web site is inconsistent due to the presence of a number of embedded systems (such as the catalogue) which are not so easily customisable. For these reasons the design coupling with the library site is being weakened, and a derived but unique design will replace the old. 


\subsection{Repository management}

Providing the ERA as a service is similar to providing any other form of institutional, Web-based service. There are technological considerations such as hardware and underlying software and how these are supported; backup and disaster recovery as well as administrative and management. The latter two of these can prove to be the most challenging.

When deciding how to manage and administer the ERA decisions needed to be made on the effort spent on metadata checking, verifying and administering policies for users, setting up new collections, and correcting post-submission errors, as well as defining the archive structure, obtaining new content and digitising retrospective content.

Various solutions were found. Checking of metadata quality is now embedded in the cataloguing service of EUL. Detailed documentation and troubleshooting guides have been produced to deal with almost every part of standard service maintenance. Tasks which fall outside the normal bounds of library and administrative work are dealt with by a group of individuals with the relevant IR knowledge and experience. These tasks include decisions regarding the state and development of the system as well as liaising with academic departments. An informal ERA Management Group (EMG), consisting of both software and library professionals, has been set up. This group is responsible for administering which institutional units are represented in the repository, obtaining content, influencing university regulations with regard to etheses management and implementing functional requirements.

\subsection{Advocacy: content recruitment strategies}

As IRs are increasingly being developed by institutions to showcase their research output online it has been realised that content does not automatically flow into the archives through the process of author 'self-archiving'. Consequently, a number of studies have been carried out to investigate working practices (Foster and Gibbons, 2005; Andrew, 2003; Hey, 2004).

It has been necessary for early adopters of IRs to augment their modest repository content by developing and testing a number of content recruitment strategies which engage faculty directly. These practical strategies have predominantly been targeted at other types of research output, e.g. e-prints, rather than the traditional thesis literature (Mackie, 2004; Markland, 2005). Successful strategies include targeting departments with ready content, seeking high-value exemplary or historical content, or a mediateddeposit service. At the annual International Symposium on ETDs organised by the NDLTD, a recurring theme that all the successful institutions have been strongly advocating is the need to mandate electronic submission of doctoral theses. One of the main differences observed between North American and European universities is that the impetus for change seems to be primarily driven from Graduate School teaching organisations in North America, whereas in countries like the UK, academic libraries have played a more central role in championing the e-theses cause. 
One of the major content recruitment avenues that EUL has been actively pursuing is persistent lobbying for postgraduate degree regulation change at the highest level to mandate that students submit their theses in both electronic and print forms. This regulation is yet to be finally ratified but it is expected that the University Senate will agree to the changes for 2005/6 and thus mandatory submission of e-these would start to take effect around 2008/9. Changing university regulations can be a notoriously slow business, involving numerous committee and sub-committee meetings.

Another approach that has been used to encourage students to deposit their etheses in the ERA has been a 'deal' whereby the EUL has offered to print one of the copies of the thesis required by university regulations in order to save the students money and encourage them to use the service.

However, already a number of students have submitted theses to the ERA, and academics have also submitted items. The feedback from the student body seems largely in favour of online submission, and many students have sought out the service without it being directly advertised to them.

\subsection{Mediated submission}

Mediated submission has been warmly welcomed by postgraduate students and academics not just in the field of e-theses, but also for other research materials. The mediated deposit service involves the submitter passing to the EUL an electronic copy of the item to be placed in the repository. A member of the ERA project staff then checks the copyright status of the work, converts any file formats as necessary, and submits the item to the relevant collection with the relevant metadata.

This sort of service requires a large administrative overhead, and the long-term sustainability is a question currently being considered. However the ERA is considered a core library service and features prominently in the Edinburgh Universities Knowledge Management strategy (Hayes, 2004). Given that the task of actually submitting on behalf of another is not too complex, documentation describing the process has been developed, and the hope is that the work can be delegated to sectors of the library which are not necessarily specialists in IRs.

\subsection{Usage statistics for the ERA}

The success of the ERA can be measured in some way by examining the system usage statistics to see how much the system is being used, which items are most popular, and which of the more unusual aspects of the service are being accessed. Figure 5 provides a breakdown of the number of items viewed in total during the first eight months of operation (June 2004-January 2005). Figure 6 provides a breakdown of the average of the number of times each item has been viewed in each of the eight months and Figure 7 looks at the use made of the three most popular items (referred to as items 1842/289, 1842/501 and 1842/498) in the ERA.

Take in Figure 5

Take in Figure 6

Take in Figure 7 
Figure 5. Overall usage statistics for ERA for June 2004 to January 2005

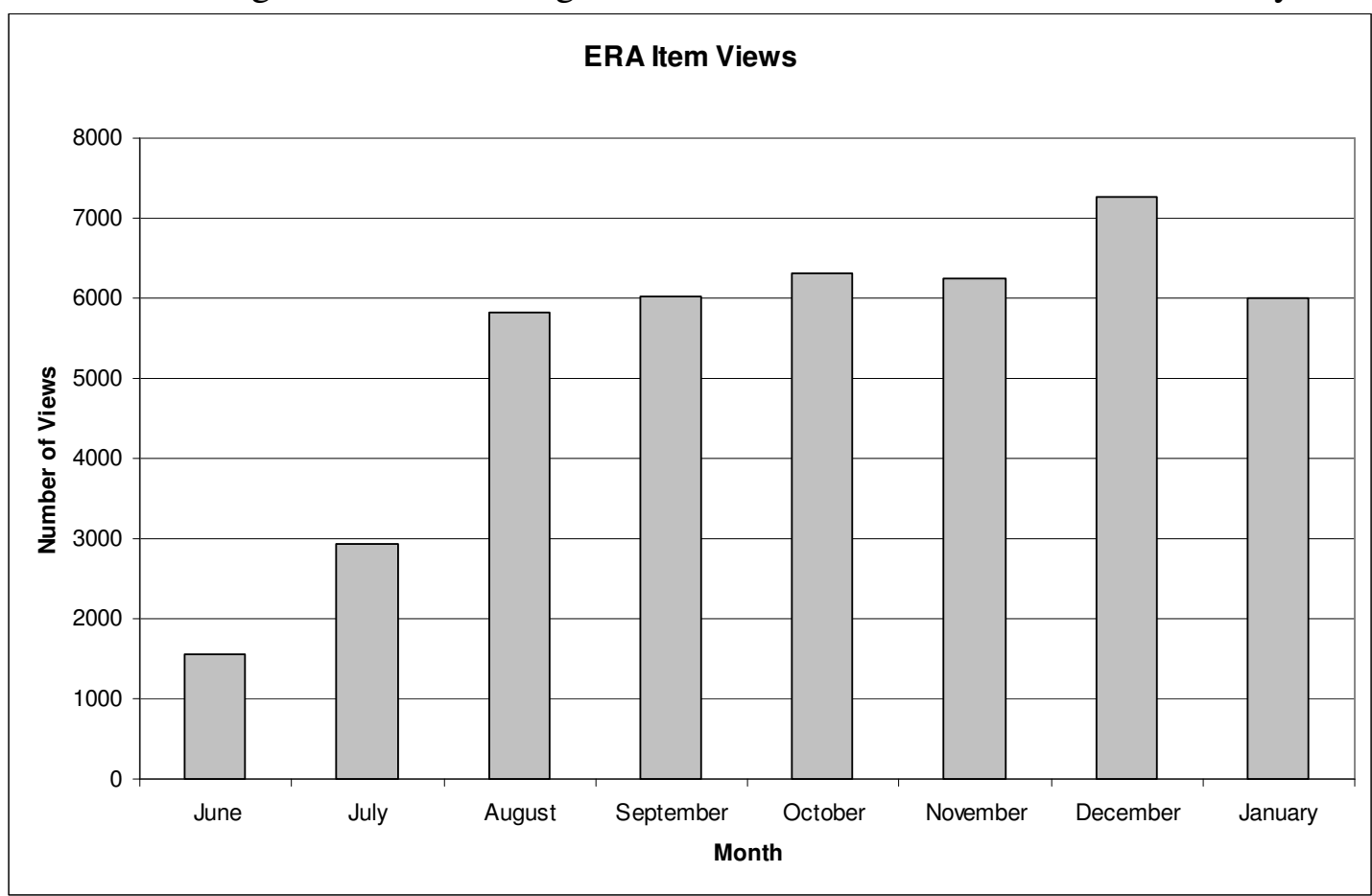

Figure 6: Average views per item in the ERA each month from June 2004 to January

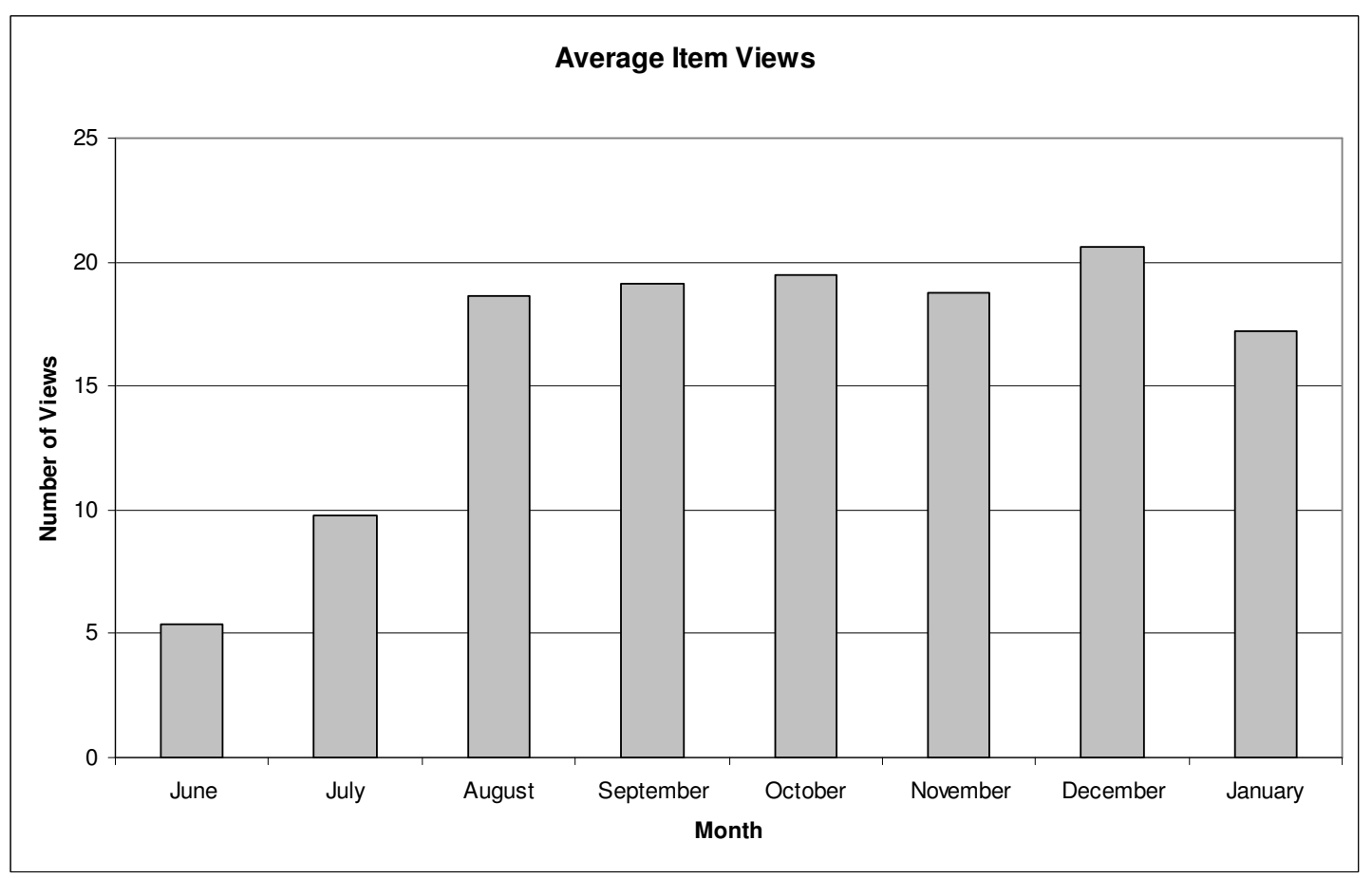

Figure 7. The usage of three popular items 


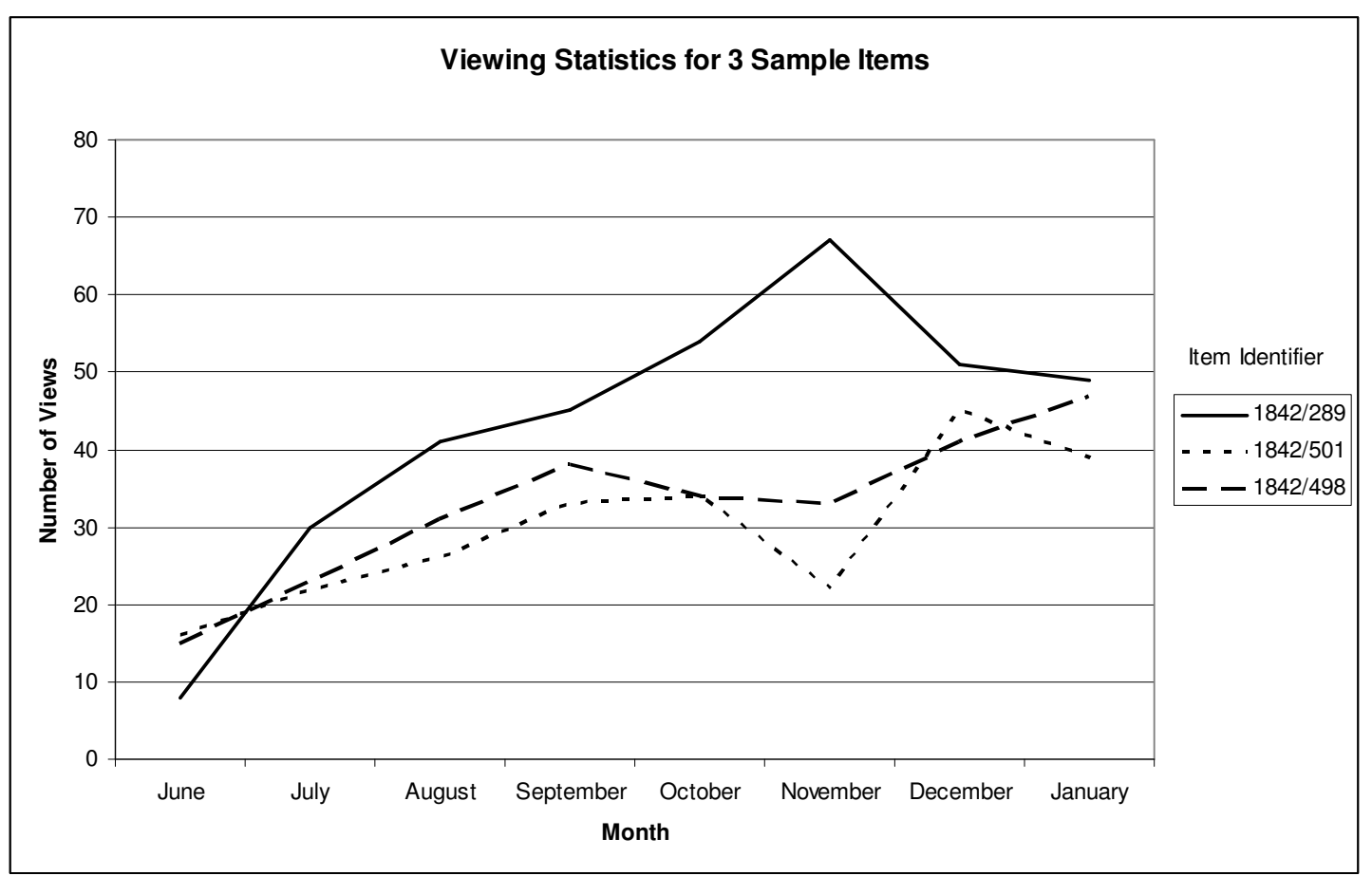

There is significant uptake of usage during the eight months for which data exists. Although it is difficult to be sure of the purpose of these item views, and which views are perhaps Web crawling software indexing for search engines these are still encouraging figures. A continual rise in the viewing statistics is expected, linked in some way to the size of the ERA which is currently still quite small at 424 items.

A number of efforts ( on software, documentation, administration, legal aspects and advocacy) have been undertaken to take the ERA from conception to completion. The above statistics suggest that cumulatively these efforts have gone to provide a valuable service which is genuinely proving of use to people.

\section{Conclusions and the future for e-theses at Edinburgh, Tapir and ERA}

Theses Alive! addressed a wealth of other activities the significance of which was not initially realised. These included areas such as:

- advocacy, not only of the service, but of the idea of open access ;

- licensing, copyright and other intellectual property issues;

- open source software development, maintenance and delivery;

- post-production service administration and continued technical support.

This paper has delivered a detailed reflection and discussion of some of the most interesting and involved areas that were considered during the course of the project including the hidden implications of delivering open access status to the theses literature and the relationship between the open access movement and the open source ethos, under which the software tools to achieve the project's aims were developed. The production of an e-theses service within the UK is relatively novel and EUL has been actively involved through the E-Theses Alive! project and the ERA service with current developments in this area. A number of other UK institutions are also developing IRs and the JISC-funded project Ethos (Electronic theses Online Service) 
aims to deliver, a fully operational, easily scaleable and financially viable prototype UK e-theses online service, and supporting infrastructure, that will enable students, researchers and other end users to search a database of theses in the UK and then to access the full-text of these theses. Ethos is scheduled to run for 18 months and started in January 2005. EUL is a partner in this project which builds upon the work carried out during the Theses Alive!, DAEDALUS and Electronic Theses projects and includes collection of e-theses at the institutional level, delivery of the records to a central database, as well as a number of tools to aid preservation and discovery. On top of this there is additional research being done into areas such as rights, royalties and permissions.

Staff from EUL are also working with the NDLTD DSpace Implementers Group, and the DSpace committer group and the Tapir looks set to be included in a significant way into future releases of the standard DSpace package.

The future, then, of the Tapir, is to provide the first steps within DSpace to explicitly handle e-theses, while the future of the ERA is to continue to provide those facilities in a production status, and to expand to store as much of Edinburgh University's research output in whatever form it might take. This could extend to providing remote storage facilities to other university services such as academic portfolios, or elearning frameworks (Lynch, 2003).

Theses Alive! has delivered much more than was originally anticipated, and came at a time when interest in e-theses in the UK was high. The result was a highly successful project with implications not only for the UK, as originally intended, but for the international community. Interest from the NDLTD as well as many European institutions has ensured that the work done during this project will continue to be developed both by EUL and the international ETD community.

\section{References}

(All URLs were checked on $3^{\text {rd }}$ March 2005)

Andrew, T. (2003), "Trends in Self-Posting of Research Material Online by Academic Staff", Ariadne, Issue 37. Available at: http://www.ariadne.ac.uk/issue37/andrew/

Andrew, T. (2004), "Intellectual Property and Electronic Theses" JISC Legal Information Service Briefing Paper. Available at:

http://www.jisclegal.ac.uk/publications/ethesesandrew.htm

Andrew, T. Jones, R. D. and MacColl, J. (2005) "Theses Alive! Completion report" JISC internal document. < is this available anywhere?>

Awre, C. (2004), "The JISC's FAIR Programme: disclosing and sharing institutional assets" Learned Publishing Vol. 17 No.2, pp. 151-156. Available at: http://eprints.rclis.org/archive/00001331/

Electronic Theses Project (2003), "Metadata core set for ETDs". Available at: http://www2.rgu.ac.uk/library/guidelines/metadata.html 
Foster N. F. and Gibbons, S. (2005), "Understanding Faculty to Improve Content Recruitment for Institutional Repositories", D-Lib Magazine. Vol. 11, No. 1. Available at: http://www.dlib.org/dlib/january05/foster/01foster.html

Free Software Foundation (2004), "The Free Software Definition". Available at: http://www.gnu.org/philosophy/free-sw.html

FreeBSD (2003), "The 4.4BSD Copyright" Available at: http://www.freebsd.org/copyright/license.html

Green, D.H and Powell, S. D. (2005), "Doctoral Study in Contemporary Higher Education", Oxford UniversityPress, OxfordIn press.

Hayes, H. (2004), "The University of Edinburgh's Knowledge Management Strategic Plan (Edition 1)". Available at: http://www.kmstrategy.ed.ac.uk/

Hey, J. (2004), "Targeting Academic Research with Southampton's Institutional Repository" Ariadne, Issue 39. Available at: http://www.ariadne.ac.uk/issue40/hey/

JISC (2001), "Standards and Guidelines to Build a National Resource" Available at: http://www.jisc.ac.uk/index.cfm?name=projman_standards

Jones, R. (2003), "DSpace vs ETD-db: Choosing software to manage electronic theses and dissertations", Ariadne, Issue 38. Available at:

http://www.ariadne.ac.uk/issue38/jones/

Jones, R. (2004), "The Tapir: Adding E-Theses functionality to DSpace", Ariadne, Issue 41. Available at: http://www.ariadne.ac.uk/issue41/jones/

Lynch, C. (2003), "Institutional Repositories: essential infrastructure for scholarship in the digital age", ARL Bimonthly Report No. 226. Available at: http://www.arl.org/newsltr/226/ir.html

Mackie, M. (2004), "Filling Institutional Repositories: Practical strategies from the DAEDALUS Project", Ariadne, Issue 39. Available at: http://www.ariadne.ac.uk/issue39/mackie/intro.html

Markland, M. (2005), "Synthesis of the responses by SHERPA Project Officers to the CERLIM Evaluation Questionnaire", Internal SHERPA project documentation. ????

Nixon, W. (2003), "DAEDALUS: Initial experiences with EPrints and DSpace at the University of Glasgow", Ariadne, Issue 37. Available at: http://www.ariadne.ac.uk/issue37/nixon/

Open Society Institute (2004), "A Guide to Institutional Repository Software". Available at: http://www.soros.org/openaccess/pdf/OSI_Guide_to_IR_Software_v3.pdf 
Stallman, R. (2002), Free Software, Free Society: Selected Essays of Richard M. Stallman, GNU Press

Suber, P. (2005), "Open Access Overview". Available at:

http://www.earlham.edu/ peters/fos/overview.htm

Wheatley, P. (2003), "A way forward for developments in the digital preservation functions of DSpace: options, issues and recommendations". Available at:

http://dspace.org/news/articles/DpAndDSpace.pdf 